\title{
Quality Research in MOOCs
}

\author{
Bing $\mathrm{Wu}^{1}$, Chenyan Zhang ${ }^{2}$ \\ ${ }^{1}$ School of Economics and Management, Tongji University, Shanghai, China \\ ${ }^{2}$ Logistics Research Center, Shanghai Maritime University, Shanghai, China
}

Keywords: MOOCs, Online learning systems, Instructional Quality

Abstract. This article focuses on a review of quality research in MOOCs from science citation index expanded (SCI-EXPANED) and Social Sciences Citation Index (SSCI) database on web of science, concerning the rapid growth of interest in understanding MOOCs. Research results indicate that (1) the number of citations on these topics mainly distributes in recent 4 years, reaching climax of 24 in 2015; (2) the main research territory is SPAIN, accounting for $41.667 \%$, then followed by GERGMAN of $16.667 \%$; (3) the year of published articles distributed between 2013 and 2016; (4) in the view of organizations, both RHEIN WESTFAL TH AACHEN and UNIVERSIDAD PABLO DE OLAVIDE have the same record count of 2, accounting for $16.667 \%$ respectively; (5) $58.333 \%$ of the research focused in education educational research, then $41.667 \%$ in computer science; (6) The number of article is of the same as that of proceedings paper, accounting for $50 \%$. Overall, the related research topics can be classified into four aspects: classification of MOOCs Criteria, design quality, instructional quality and strategies for enhancing quality.

\section{Introduction}

Massive Open Online Courses (MOOCs) have gained a lot of attention in recent years as a major advancement of higher education [1]. Millions of people are learning in hundreds of MOOCs offered by universities and other public and private organizations worldwide [2].

Several studies have reported discrepancies and questions about the pedagogical problems concerning assessment and feedback [3]. Although a large set of criteria to the successful design of online learning systems has been identified in general, not all of them can be used in the MOOCs context, due to unique features of MOOCs. Therefore, some dimensions and implications of MOOCs evaluation need to be assessed and analyzed from different perspectives [4].

Specific concerns puts the emphasis on accessing to high quality content rather than paying attention to instructional design and the overall learning experience [5-6]. However, there is no recognized system for quality measurement and even the metrics for measuring are under debate.

The rest of this article is organized as follows: Section 2 surveys the relating results analysis of quality research in MOOCs literatures. Section 3 briefly summarizes related work within this topic. Section 4 concludes the article with a summary of our key results and discusses new opportunities for future research.

\section{Analysis Results of Relating Literatures}

According to Science Citation Index Expanded and Social Sciences Citation Index Database in web of science, 12 articles title as "MOOCs quality" including the conferences papers are found in related discipline in recent four years.

Results of Citation Report. Published items in each year were shown in Fig 1, which illustrated the tendency of increased research from 2013, reaching climax in 2015 of 8. Accordingly, citations increased from 2014 and the highest citations of 24 happened in 2015, as shown in Fig 2. 


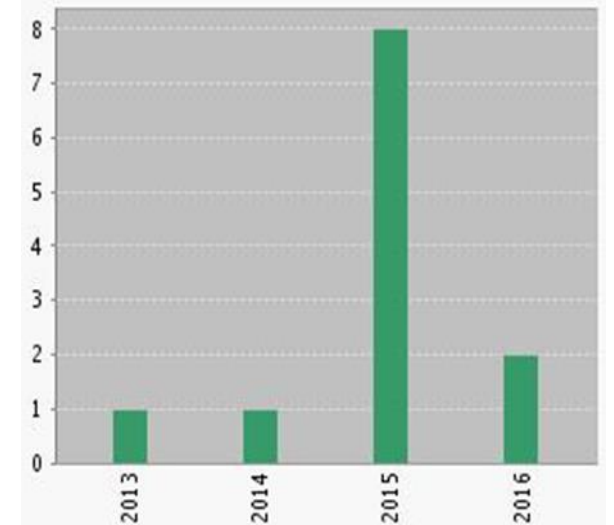

Fig 1.Published Items in Each Year

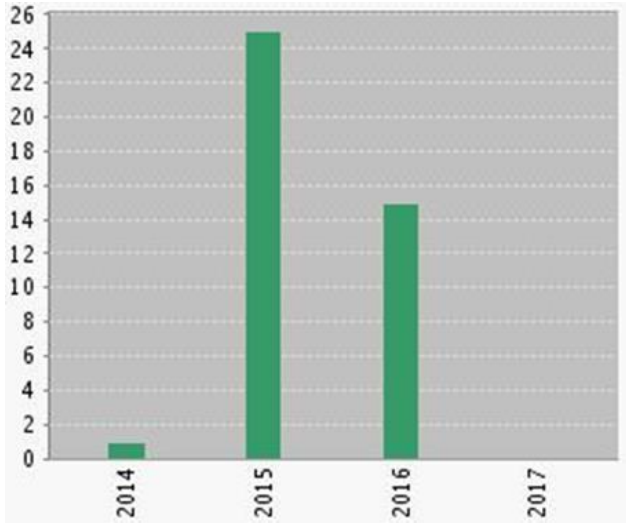

Fig 2. Citations in Each Year

Results of Countries/Territories. According to Table 1 of the analysis of countries/territories, SPAIN and GERMANY ranked in Top 2. Especially, SPAIN accounts for 41.667\%, and GERMANY accounts for $16.667 \%$.

Table 1. Countries/Territories

\begin{tabular}{ccc}
\hline Countries/Territories & Record Count & $\%$ of 12 \\
\hline SPAIN & 5 & $41.667 \%$ \\
GERMANY & 2 & $16.667 \%$
\end{tabular}

Results of Organizations. In the view of organizations, both RHEIN WESTFAL TH AACHEN and UNIVERSIDAD PABLO DE OLAVIDE have the same record count of 2, accounting for $16.667 \%$ respectively in Table 2 .

Table 2. Organizations

\begin{tabular}{ccc}
\hline Organizations & Record Count & $\%$ of 12 \\
\hline RHEIN WESTFAL TH AACHEN & 2 & $16.667 \%$ \\
UNIVERSIDAD PABLO DE OLAVIDE & 2 & $16.667 \%$ \\
\hline
\end{tabular}

Results of Publication Years. In line with the published items in each year of Figure 1, 83.334\% researches were published between 2015 and 2016, as shown in Table 3.

Table 3. Publication Years

\begin{tabular}{rcc}
\hline Publication Years & Record Count & $\%$ of 12 \\
\hline 2015 & 8 & $66.667 \%$ \\
2016 & 2 & $16.667 \%$ \\
\hline
\end{tabular}

Results of Research Areas. According to Table 4, 58.333\% of the research focused in EDUCATION EDUCATIONAL RESEARCH, then $41.667 \%$ in COMPUTER SCIENCE.

Table 4. Research Areas

\begin{tabular}{ccc}
\hline Research Areas & Record Count & $\%$ of 12 \\
\hline EDUCATION EDUCATIONAL RESEARCH & 7 & $58.333 \%$ \\
COMPUTER SCIENCE & 5 & $41.667 \%$ \\
\hline
\end{tabular}

Results of Document Types. Generally, there are two document type. The number of article is of the same as that of proceedings paper, accounting for 50\%, as shown in Table 5.

Table 5. Document Types

\begin{tabular}{ccc}
\hline Document Types & Record Count & $\%$ of 12 \\
\hline ARTICLE & 6 & $50.000 \%$ \\
PROCEEDINGS PAPER & 6 & $50.000 \%$ \\
\hline
\end{tabular}

Results of Web of Science Categories. Education educational research ranks in the top 1, accounting for 58.333\%. Then categories existing in COMPUTER SCIENCE INFORMATION SYSTEMS, COMPUTER SCIENCE INTERDISCIPLINARY APPLICATIONS and COMPUTER SCIENCE THEORY METHODS account for $25 \%, 16.667 \%$ and $16.667 \%$ respectively, as shown in Table 6. 
Table 6. Web of Science Categories

\begin{tabular}{ccc}
\hline Web of Science Categories & Record Count & $\%$ of 12 \\
\hline EDUCATION EDUCATIONAL RESEARCH & 7 & $58.333 \%$ \\
COMPUTER SCIENCE INFORMATION SYSTEMS & 3 & $25.000 \%$ \\
COMPUTER SCIENCE INTERDISCIPLINARY & 2 & $16.667 \%$ \\
APPLICATIONS & & \\
COMPUTER SCIENCE THEORY METHODS & 2 & $16.667 \%$ \\
\hline
\end{tabular}

Results of Authors. As shown in Table 7, five authors are responsible for $83.335 \%$ of the published items, averagely of $16.667 \%$.

Table 7. Authors

\begin{tabular}{ccc}
\hline Authors & Record Count & $\%$ of 12 \\
\hline CHATTI MA & 2 & $16.667 \%$ \\
SCHROEDER U & 2 & $16.667 \%$ \\
SILVERA JLS & 2 & $16.667 \%$ \\
WOSNITZA M & 2 & $16.667 \%$ \\
YOUSEF AMF & 2 & $16.667 \%$
\end{tabular}

Results of Group Authors. 25\% of authors are IEEE, as shown in Table 8.

Table 8. Group Authors

\begin{tabular}{ccc}
\hline Group Authors & Record Count & $\%$ of 12 \\
\hline IEEE & 3 & $25.000 \%$ \\
\hline
\end{tabular}

\section{Relating Topics of Quality in MOOCs}

We review areas of research covered by papers in quality of MOOCs to take the current state and to propose directions for future research. Generally, relating topics and be identified from five aspects: classification of MOOCs Criteria, design quality, instructional quality and strategies for enhancing quality in MOOCs.

Classification of MOOCs Criteria. To identify specific criteria to assure the design quality of MOOCs from both learners' and teachers' perspectives. Based on an extensive literature review, the classification of MOOC criteria is proposed as depicted in Figure 1 [6]. The criteria is categorized into the 2 dimensions of pedagogy and technology.

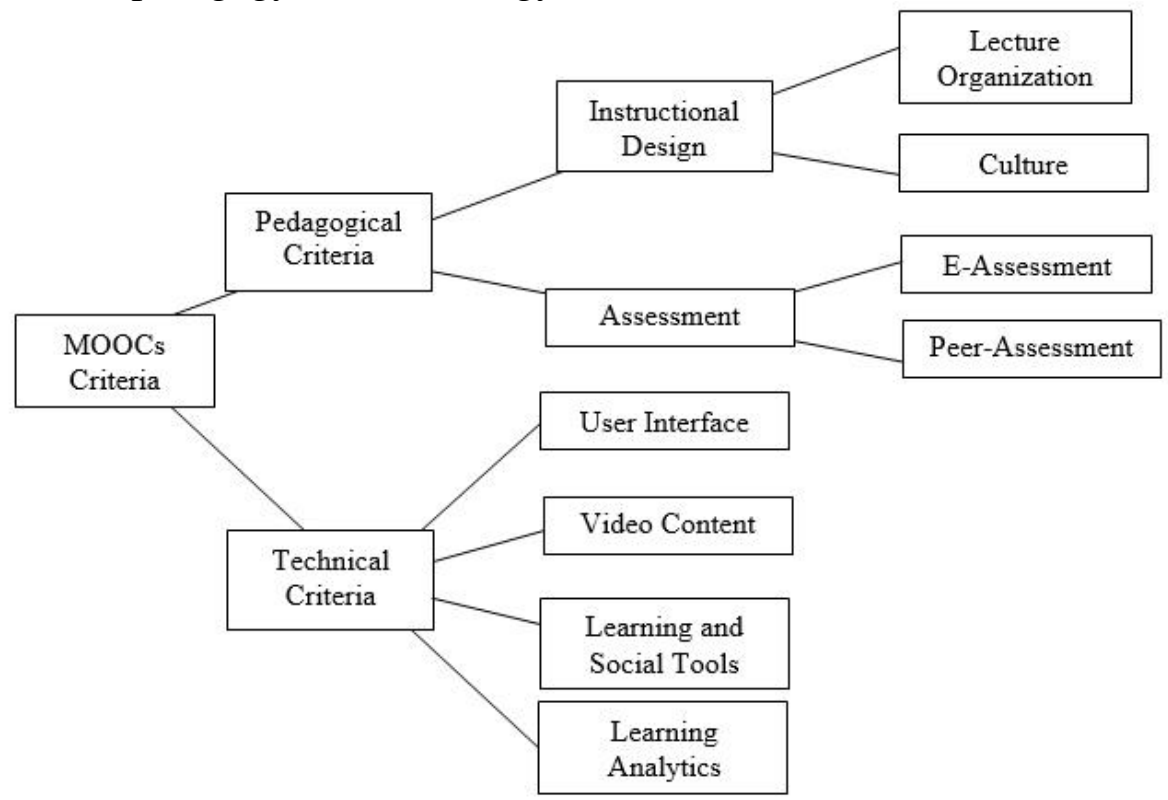

Fig 1. Classification of MOOCs criteria 
Design Quality. Based on a large survey including learners as well as professors both with MOOC experience, the results of reference [6] showed that learning analytics and assessment have obtained the highest average mean scores, which reflects the importance of learning analytics and assessment as key features in MOOCs.

Instructional Quality. An analysis of instructional design quality of randomly selected MOOCs is presented by using a course survey instrument [7-8]. Two types of MOOCs (xMOOCs, which primarily based around interaction with content and essentially adopting a behaviorist learning approach, and cMOOCs, which focus on harnessing the power of social media and interaction with peers) were analyzed and their instructional design quality was assessed and compared to disclose that the majority of MOOCs scored poorly on most instructional design principle, although most MOOCs scored highly on organization and presentation of course material [9-10].

Strategies for Enhancing Quality. It argues that the current discourse around the concept of xMOOCs and cMOOCs, is an inadequate way of describing the variety of MOOCs and the ways in which learners engage with them [11-12]. Thus, an alternative means of categorizing MOOCs, based on their key characteristics and the key stakeholders, is introduced by describing the Learning Design framework, which can be used to design more pedagogically informed MOOCs to enhance the learner experience and ensure quality assurance.

\section{Conclusions}

Although some pedagogical and design approaches are proposed to bring quality to MOOCs that expect to be useful in some way, more accurate and validated principles as basis of instructional design in MOOCs should be established. And future research could investigate instructional rationale, goals and motivations underpinning in MOOCs. In addition, more detailed investigation on the effect of design should be carried out in groups of respondents with different characteristics.

\section{References}

[1] Adair, D., Alman, S. W., Budzick, D., Grishman, L. M., Mancini, M. E., \& Thackaberry, S. (2014). Many shades of MOOCs. Internet Learning, 3(1), 53-72.

[2] Behr, D., Bandilla, W., Kaczmirek, L., \& Braun, M. (2014). Cognitive probes in Web surveys on the effect of different text box size and probing exposure on response quality. Social Science Computer Review, 32, 524-533.

[3] Sangrà, A, \& Wheeler, S. (2013). New Informal Ways of Learning: Or Are We Formalising the Informal? RUSC. Universities and Knowledge Society Journal, 10(1), 107-115.

[4] You, J., Hochlberg, S. A., Ballard, P., Xiao, M., \& Walters, A. (2014). Measuring online course design: A comparative analysis. Internet Learning, 3(1), 35-52.

[5] Yousef, A. M. F. Chatti, M. A. Schroeder, U. Wosnitza M. and Jakobs, H. (2014). MOOCs - A Review of the State-of-the-Art. Proceedings of the CSEDU 2014 conference, 3, 9-20. INSTICC, 2014.

[6] Yousef, A. M. F., Chatti, M. A., Schroeder, U., Wosnitza, M. (2014). What Drives a Successful MOOC? An Empirical Examination of Criteria to Assure Design Quality of MOOCs. 2014 14th Ieee International Conference on Advanced Learning Technologies, 44-48

[7]Conole, G. (2016). MOOCs as disruptive technologies: strategies for enhancing the learner experience and quality of MOOCs. Red-Revista De Educacion a Distancia, 50, 1578

[8] Morris, L. V. (2013). MOOCs, emerging technologies, and quality. Innovative Higher Education, Springer, 38, 251-252

[9] Sandeen, C. (2013). Assessment's place in the new MOOC world. Research \& Practice in Assessment Journal, 8, 5-13 
[10] de Barba, P. G., Kennedy, G. E., Ainley, M. D. (2016). The role of students' motivation and participation in predicting performance in a MOOC. Journal of Computer Assisted Learning, 32(3), 218-231

[11] Amo, D. (2013). MOOCs: Experimental Approaches for Quality in Pedagogical and Design Fundamentals. First International Conference on Technological Ecosystem for Enhancing Multiculturality, 219-223

[12]Margaryan, A., Bianco, M., \& Littlejohn, A. (2015). Instructional quality of Massive Open Online Courses (MOOCs). Computers \& Education, 80, 77-83. 